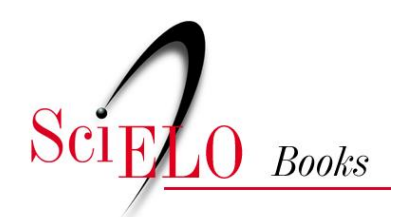

\title{
¿Qué es la verdad? \\ Una breve aproximación al sentido de la verdad en Heidegger y Levinas
}

\author{
Víctor Adolfo Iza Villacís
}

\section{SciELO Books / SciELO Livros / SciELO Libros}

IZA VILLACÍS, V.A. ¿Qué es la verdad? Una breve aproximación al sentido de la verdad en Heidegger y Levinas. In: IZA VILLACÍS, V.A., ed. Persona, educación y filosofía: reflexiones desde la educación universitaria [online]. Quito: Editorial Abya-Yala, 2018, pp. 143-153. ISBN: 978-997810-493-4. https://doi.org/10.7476/9789978104934.0009.

All the contents of this work, except where otherwise noted, is licensed under a Creative Commons Attribution 4.0 International license.

Todo o conteúdo deste trabalho, exceto quando houver ressalva, é publicado sob a licença Creative Commons Atribição 4.0.

Todo el contenido de esta obra, excepto donde se indique lo contrario, está bajo licencia de la licencia $\underline{\text { Creative }}$ Commons Reconocimento 4.0. 


\section{¿Qué es la verdad? \\ Una breve aproximación al sentido de la verdad en Heidegger y Levinas}

Víctor Iza Villacís ${ }^{1}$

\section{Resumen}

Tratar de comprender la verdad es algo muy delicado, Heidegger lo presenta desde el sentido del ser, aquel instante de tiempo, ese "estar ahí" donde el horizonte encuentra su sentido. Levinas da un sentido diferente a la ontología; a ese giro dado por Heidegger de la fenomenología a la hermenéutica y propone una mirada desde otro ámbito y otro sentido que recae en el Otro. La verdad en la comprensión del otro. El ser carece de certeza y de verdad sin el otro.

Siguiendo una ruta analítica de textos se procura presentar una aproximación brevísima sobre estos dos grandes pensadores, quienes seguramente dejan con la "necesidad" de descubrirlos en la inmensidad filosófica de sus obras, que solo el arte de la palabra en la poesía puede ilustrar someramente la inmensidad y la intensidad de la verdad.

Palabras claves: Horizonte de sentido, otredad, proyecto, rostro, verdad.

1 Master en Filosofía por la Universidad Pontificia Bolivariana de Medellín Colombia. Doctorando en Filosofía por la Universidad Pontificia Bolivariana de Medellín Colombia. Master en Pastoral Universitaria por la Universidad Salesiana del Ecuador. Catedrático de las materias humanísticas en la UPS sede Guayaquil. viza@ups.edu.ec 


\section{Abstract}

Trying to understand the truth is very delicate, Heidegger presents it from the sense of self, that moment of time, that "being there" where the horizon is meaningless. Levinas gives a different meaning to the ontology; that spin given by Heidegger phenomenology to hermeneutics and proposes a view from another area and another in the sense that falls further. The truth in the understanding of the other. It is devoid of certainty and truth without the other.

Following an analytical path texts seeks to provide a brief approach on these two great thinkers who surely left with the "need" to discover the philosophical immensity of his works, that only the art of the word poetry can illustrate briefly the immensity and intensity of the truth.

Keywords: Horizon of meaning, otherness, draft, face, true.

\section{Introducción}

El recorrido por la comprensión no necesariamente natural de la verdad sino como conocimiento y abstracción de algo profundamente humano que se vuelve "artificialmente necesario" comprenderlo a través de la historia, tiene un largo camino.

En este recorrido se encuentra la obra de García (2004), donde presenta algunos sistemas en torno al tema de la verdad a través de la historia, que permiten una comprensión rápida, fácil y certera.

Para dar comienzo se observa el Escepticismo que según García "aceptaba la adecuación de sujeto con el objeto, pero niegan la cognoscibilidad y la justificación de la adecuación en sí misma" (2004). Existe una "coherencia" pero no se puede conocer exactamente esa adecuación ni justificarla en el sentido pleno. O como bien menciona Cresto (1997) en el escepticismo hay premisas que no se puede conocer y otras en que no es posible conocer. Esa duda escéptica que tanto bien le hace al misterio de la verdad porque la deja en ese espacio en el cual es mejor la vida en ataraxia. 
García (2004) continúa el breve recorrido con el idealismo-subjetivismo que reflexiona profundamente acerca de la noción de la verdad. Noción como ese instante de racionalidad pero que es netamente subjetivo, propio del sujeto y de la cosa. Seguidamente nos indica que el idealismo explica que "verdadero es todo lo que en sí no encierra contradicción alguna. Ya no es exigible la conformidad del sujeto cognoscente con el ser, sino conformidad con las leyes mentales, porque en definitiva, el objeto es totalmente inmanente al sujeto" (2004, p. 56). Lo que da coherencia al objeto no es el sujeto ni lo que piensa sobre él sino las cualidades esenciales del mismo objeto que es el sujeto mismo.

El recorrido prontamente menciona al positivismo, que en premisa de sus seguidores "limitan el campo de la verdad, pues la verdad noumenal (que pertenece a la intuición intelectual no sensible, Kant), nos es desconocida absolutamente" (García, 2004, p. 57). Por el solo hecho de que la verdad es en sí y no puede ser pensada o representada. "Plantean un reduccionismo de la verdad constreñida al puro fenomenismo, ya que solo se conocen las representaciones, controlables por criterios subjetivos" (p. 57).

Es el caso especial de Husserl para quien la: "Fenomenología misma se presenta como autorreflexión de la humanidad al servicio de una praxis racional universal, de un impulso cada vez más libre que se encamina hacia la idea de una humanidad que quiere existir y vivir en la verdad y la autenticidad" (Ortiz, 1984, p. 231).

¿A quién no le gustaría permanecer en la verdad sin encaminarse a ella? Pero ¿qué significaría esto de permanecer en el sentido de la verdad y la autenticidad? ¿Cómo podríamos comprender ese anhelo de humanidad? En Husserl encontramos esa fenomenología profundamente humana y reflexiva que rompe con el positivismo de la época y que dará paso a que Heidegger pueda relacionar su ser y tiempo sobre algunos elementos Hurselianos.

Siguiendo el proceso de reconocimiento aparece el "Relativismo que presenta múltiples sistemas. La verdad no es un valor de 
conocimiento absoluto, sino que depende. Depende de una verdad por aproximación o verdad simbólica, de la experiencia frente a una verdad inamovible o trascendental" (García, 2004, p. 57).

Por último sin dejar de ser importante el irracionalismo que "no se atiende a la adecuación como elemento formal. Es decir a la coherencia sujeto objeto. Considera que la verdad no se puede conocer por vías racionales e intelectuales, y hay que conocerla mediante proceso analógico e irracional" (2004, p. 57). La verdad se puede decir "salta" de la categoría racional, no es un objeto de estudio racional, por el contrario para conocerla se necesita otros métodos como la analogía.

\section{Heidegger la verdad en libertad}

En 1927 Heidegger da a conocer "ser y tiempo" y con este fecundo texto sitúa al ser en el ahí, el Dasein. Comprendiendo por Dasein el estar-en-el-mundo y no solo en pensar como lo relacionaba Descartes, pienso y luego existo, sino en realmente ser concientes de esta fijación en el tiempo como seres en estado ahí. En este sentido, Acevedo expresa acerca del Dasein como "fijar la mirada en el estar-en-el-mundo nos hace caer en la cuenta de que nuestra vida cotidiana tiene una especial relevancia... Nuestro estar-en-el-mundo se da, inmediata y regularmente, en el modo de la cotidianidad" (Acevedo, 2010, p. 32).

Este elemento diferenciador de la filosofía de Heidegger permite la comprensión de que la verdad se presente como un desvelarse el ser, y el error como un ocultamiento del ser y que sin embargo no deja de ser verdad (Heiddeger, 2009). Es decir que las dos realidades son esenciales al ser, es la verdad la que se desvela en el ser mismo, pero ¿cuándo? Ahora, en este instante. La verdad y el error están en íntima correlación con el conocimiento. ¿Cuál conocimiento? ¿El conocimiento racional o el conocimiento del ser que se desvela? ¿Este conocimiento debe tener una congruencia, debe ser consecuente o simplemente ser? Es conocimiento fenomenológico pero en movimiento develado y ocultado, que debe ser interpretado, he ahí el movimiento de Heidegger que pasa de la fenomenología a la hermenéutica como 
bien lo hace notar León (2009) es su estudio sobre este giro. Por esto el error se caracteriza por su falsa certeza, es decir es en el orden del pensamiento la contradicción, o en otras palabras, se pretende atribuir a un sujeto un predicado que no le corresponde y no le conviene.

Desde el punto de vista del hombre como proyecto en Heidegger es posible comprender que la verdad no es algo que el ser tenga o algo que el hombre piense, o algo que el hombre diga, es el ser mismo, y cuando este ser se "carga" de predicados que no le corresponde es un ente, se convierte en un ser óntico.

¿De qué depende que el hombre sea lo que es y permanezca en la verdad de sí mismo y esa verdad se devele sin error en toda su existencia?

Para Heidegger esta verdad de sí mismo se presenta en el horizonte de comprensión o la opción fundamental. Es en este caso el preciso momento en que el ser y la verdad hacen morada. El ser habita en ella. Y el ser se hace proyecto desde su libertad.

Parece que Heidegger deja un movimiento "claro oscuro" de la realidad polarizando al ser entre dos circunstancias que se mueven constantemente, que se develan y que se ocultan, incluso el ser mismo es ahí, Dasein y sin embargo puede llegar a ser distinto a lo que le corresponde ser, sin llegar a no ser sino simplemente a no tener correspondencia, es decir a no vivir en la certeza o en la verdad.

Sin embargo este movimiento no es devenir alterado o incongruente, necesita de un elemento que aparece en su comprensión de la verdad que es la libertad. Dejemos que Heidegger hable:

La libertad no es la falta de ataduras que permite poder hacer o no hacer. Pero la libertad tampoco es la disponibilidad para algo exigido y necesario (y, por lo tanto, en algún modo, ente). La libertad es antes que todo esto (antes que la libertad "negativa" y "positiva") ese meterse en el des-encubrimiento de lo ente como tal. El propio desocultamiento se preserva en el meter-se ex-sistente por el que la apertura de lo abierto, o, lo que es lo mismo, el 'aquí, es lo que es (Heidegger, 2009, p. 156). 
Se comprende entonces la libertad del ser no como un algo o un elemento cognoscitivo o virtuoso sino como el "habitar" que abre al ser en cuanto es ahí. Ahí es libertad cuando se habita en sí mismo. No es una acción ni un poseer sino un habitar en el mismo. La esencia de la verdad, entendida como conformidad del enunciado, es la libertad. Libertad en cuanto el ser es libre en la medida que habita en la verdad. Si no hubiera verdad tampoco habría libertad, sin embargo al ocultarse por el error, por algo que no corresponde a lo que es, no hay libertad en el ser y tampoco verdad sino hasta que vuelva a desocultarse, salir de su error o de su incorrespondencia. En este caso entonces habitar en la verdad sería volver al horizonte de sentido de su propia existencia.

¿Es el horizonte de sentido es una posibilidad para recuperar la esencia de la adecuación que se determina de acuerdo con la naturaleza de la relación existente entre el enunciado y la cosa? ¿Es la adecuación quien determina la verdad en el ser de manera correcta y que da paso a que el ser sea la verdad?

Para dar respuesta debemos presentar una idea de la verdad como testimonio de vida.

Permanecer en la verdad como categoría ontológica sin caer en una metafísica aislada del ser, es tratar de comprender que Heidegger nos invita a no vivir en el ocultamiento de la verdad sino en esa permanente adecuación.

Este carácter unido a la verdad es una adecuación de que el ser en el mundo, es un ser ahí y que al estar adecuadamente en su estado viviendo su esencia como proyecto habita en la verdad como congruencia de sus propias decisiones. Ese ser para otros se convierte en testimonio de la verdad, situación que otros hombres no comprenderán porque ven a la verdad como algo que se posee, como algo que no se puede comprender o como algo simbólico. Para Heidegger la verdad es la esencia del ser y esta esencia le genera carácter en el mundo. 
Y por último para comprender el carácter Heidegger presenta formidablemente el estado de ánimo que nace de la libertad como esencia de la verdad. "El dejar ser a lo ente que predispone un ánimo, penetra y precede a todo comportarse que se mantiene siempre abierto y se mueve en él" (Heidegger, 2009, p. 162). Lo abierto a "ser ahí" es el carácter del hombre que lo envuelve en su libertad para permanecer en la verdad. El estado de ánimo es la apertura plena a la totalidad donde el ser es. El proyecto como tal se descubre en el sentido de la existencia y en el sentido del ser. Aunque el hombre no sea proyecto sigue siendo ser que vive en el ocultamiento, hasta que no se encuentre en su horizonte de sentido el proyecto no aparecerá con decisión del ser. La esencia de la verdad se complementa con el carácter de proyecto del ser. Un ser que es libertad, esencia, verdad, estado de ánimo, proyecto y muerte.

\section{Levinas y la esencia de la verdad en el otro}

Lituania en 1906 vio nacer a este hombre que se atrevió a ver desde otro punto de vista el tema ontológico. No se fracciona en la fenomenología sino que oportunamente nos invita a tener otra mirada, una mirada que involucra el rostro del otro. Este rostro que para Levinas pide respuesta, es inmediatez, es "epifanía” y "revelación". "En el rostro se me hace presente el otro hombre con absoluta inmediatez, en total ausencia de intermediarios: se hace patente por sí mismo" (Giménez, 2011, p. 89).

Los escritos del filósofo Emmanuel Levinas están cargados de alteridad, es el otro el que me define, no puedo hacerlo a mí mismo sin contar con su presencia, y no es una presencia que involucre el nombre de alguien, por sí mismo el otro me define y me cuestiona, me proyecta y me retiene. Por lo tanto "no es extraño, que sus obsesiones lo lleven a desconfiar de todo atisbo de totalidad y, para ello, jamás pierde de vista la infinitud del Otro... Rostro que ríe y saluda, rostro que sufre y me exige respuesta, rostro que me seduce y cautiva" (Aguirre, 2010, p. 57). 
Comprendiendo por donde va la filosofía levisiana podemos comprender que para él es tan importante la alteridad que nos conmueve y no de una forma sensible, o romántica sino que conmociona a nuestro interior sobre la manera como nos interpretamos y por lo tanto nos comprendemos. La filosofía de Lévinas, se caracteriza por "reivindicar la no intencionalidad de la conciencia, que no buscará la verdad como un fin en sí mismo; al menos no como mera adecuación de la mente con las cosas. La verdad es identificada con la autonomía y la plenitud del ser" (Aguirre, 2010, p. 56). Y es el otro quien me engendra desde el infinito por así decirlo y otro que no tiene rostro alguno pero que en su mirada puedo descubrir la verdad, la verdad sobre mí mismo y la existencia, la verdad sobre el mundo y su totalidad. En el rostro del otro habita la certeza incluso de mi pasividad, la otredad es vuelve mismidad.

Es de esperarse que al ser "re-conocidos" en el otro y al "re-conocerlo" también podamos conocer la verdad, que no es una categoría, como lo hemos visto cognoscible o racional, sino en la "re-lación" la cual habitamos y de la cual dependemos en interrelación absoluta.

La verdad del otro en mí, es una verdad esencial que nace del corazón del Talmud que Levinas recoge como una tradición que arrebata a la primacía de la ontología de la tradición griega y que es propuesta como otra mirada por la otredad. La verdad ya no es una posesión propia del sujeto sino que se entrelaza en la relación del tu y yo, pero que no solo es de palabra o sensación, ni tampoco de racionalidad, sino de trascendencia. La verdad se vuelve el inicio ético de la persona en el otro. Es el reconocimiento del valor absoluto del otro en mí y viceversa, No es una verdad que debe ser discutida o comprendida, sin una verdad del sentido mismo de la existencia que nos arroja desde y en el otro para no ocultarnos a la respuesta ética de la vida. La verdad es ética porque nace del bien del ser que existe desde la respuesta del Otro que responde y se responsiviza por esa respuesta dada en el amor y la aceptación. No hay mera tolerancia ni inactividad, ni la sensación de indiferencia en la cual se mueve el otro, nace o se desarrolla, sino 
151

en una percepción mayor que nos fecunda a todos en el amor. El Otro nos sostiene porque es el Amor y no hay mayor verdad que habitar en el Otro que al vernos vulnerables responde frente a nuestra vacuidad y nos llena de verdad y bien. Arrojados desde esa respuesta hacia el bien, lo bello y lo bueno como lo expresa León Hebreo, quien es estudiado por Miguel García-Baró (2010) cuando desprende todo el pensamiento de Levinas desde el judaísmo. Esta fuerza inagotable de la verdad no es posesión del ser sino de la Otredad absoluta y trascendente que nos sostiene y nos totaliza, como muy bien lo presenta Levinas en Totalidad e infinito (Levinas, 1961).

\section{Conclusiones}

En la actualidad parecería que el ser se "mueve" en dirección irracional y la verdad es vista como emoción, no como permanencia, ni como habitabilidad, sino como mera consecuencia de un estado de bienestar. Si bien es cierto hemos roto limites en lo científico y tecnológico, hay un estado sombrío con respecto a lo que es la esencia de la verdad como lo menciona Heidegger "el estar del hombre, su existir, es el único sostén efectivo de su actuar, porque es también la única señal de su verdad".

¿Qué es la verdad sino el ser en libertad en apertura a la vida? todo el movimiento de esa verdad que se oculta pero que por ocultarse no significa que no está ahí, hay que descubrirla, por usar un término no tan heideggeriano. Esa verdad del ser que no se hace visible sino en el proyecto donde todo confluye para ser lo que somos sin incongruencias.

Heidegger nos alienta a la vida desde un ser concreto y con existencia plena. Este proyecto de ser no es concluyente, también se oculta y se desoculta, incluso puede habitar en la no verdad, y sin embargo es la fuerza de lo humano que lo invita a buscar ese horizonte de sentido donde la verdad hace esencia y donde el hombre es libertad. El Dasein no es un complicado concepto ontológico, la final es lo que somos construyéndonos en nuestra propia esencia. 
Y sin embargo aparece Levinas y con la fuerza de su pensamiento nos eleva a un encuentro, donde no podemos analizar la verdad desde nuestra propia conciencia, sino desde la conciencia en apertura, ligada al otro, interrelacionada. Levinas nos demuestra que la verdad no es algo que uno posea, sino que es conjunta, nos posee, no solo puede ser comprendida sino habitada o por lo menos tener la clara conciencia que somos en esencia verdad. En esa totalidad de Ser somos la verdad y en términos de Heidegger siendo en libertad somos verdad y en términos de Levinas siendo rehenes unos de otros la habitamos, somos en ella.

Según el capítulo 18 del Evangelio de Juan, Pilato estando frente a Jesús le preguntó: ¿Qué es la verdad? Y habiendo dicho esto, salió otra vez a donde estaban los judíos y les dijo: Yo no encuentro ningún delito en El. (Jn. 18, 37 -38)

¿Por qué no espera la respuesta? ¿Es tan difícil llegar a enfrentarse a la verdad porque se descubre que el poder trente a ella no tiene ningún tipo de sentido?

Tal vez Pilato se descubrió en el rostro de Cristo, tal vez algo de humanidad empezó a brotar cuando al final dice, no encuentro culpa en este hombre, queriendo decir tal vez, ¿Quién soy yo para juzgarlo? No lo sabemos. Y tampoco la respuesta a la pregunta, porque Cristo no la dice, porque no es algo que se pueda decir y ya. Es algo que se vive y se es. Y en la cual habitamos.

\section{Bibliografía}

Acevedo, J. (2010). La frase de Heidegger "la ciencia no piensa", en el contexto de su meditación sobre la era técnica. Scielo, Revista de Filosofía, 66, 5-23. Disponible en: https://goo.gl/mnnEkV.

Aguirre, J. (2010). Sufrimiento, verdad y justicia. Alpha (Osorno), 169-180. Disponible en: goo.gl/Tn3Ann

Cresto, E. (1997). Escepticismo, verdad y confiabilidad. Revista Latinoamericana de Filosofía, 93-125. Disponible en: https://goo.gl/HZ9PGR. 
García, X. (2004). El recorrido por el hombre del siglo XXI. Madrid: Salterrae.

Giménez, A. (2011). Emanuel Levinas: Humanismo del rostro. Escritos, 337-349. Disponible en: https://goo.gl/xk96DK.

Heiddeger, M. (2009). De la esencia de la Verdad. Madrid: Herder.

León, E. (2009). El giro hermenéutico de la fenomenología en Martin Heidegger. Polis Revista Latinoamericana, 22-36. Disponible en: https://goo.gl/6qvfLB.

Ortiz, R. (1984). Historia de la filosofía. Oviedo: Pentalfa. Disponible en: https://goo.gl/WnZTKg. 